\section{Vigilância à Saúde e Prevenção na Transmissão de Patógenos}

\author{
Health Surveillance and Prevention in Transmission of \\ Pathogens
}

\section{RESUMO}

A prevenção e o controle de doenças integram o sistema de saúde, e melhorias nestes setores são desejadas. As doenças veiculadas por alimentos têm âmbito cosmopolita e mudanças nos hábitos alimentares do homem podem levar a uma adaptação microbiana. A manipulação de alimentos envolve práticas que devem garantir um alimento seguro. Várias fontes podem contaminar um alimento e a emergência de microrganismos patogênicos é um resultado do impacto exercido em todos os componentes da cadeia de produção alimentar. Procedimentos de manipulação inadequados de alimentos podem explicar como patógenos colonizam e se disseminam utilizando rotas específicas, comprometendo a segurança alimentar. Esta revisão objetivou verificar os principais fatores relacionados à transmissão de patógenos, o impacto na tecnologia alimentar e a ênfase em boas práticas de manipulação de alimentos. Priorizaram-se os organismos bacterianos mais envolvidos em surtos, ressaltando-se a incidência de Escherichia coli, Salmonella spp. e Staphylococcus aureus. Pode-se constatar que há necessidade de orientação dos manipuladores e uso de programas de controle de qualidade. Maior incentivo deve ser atribuído às práticas que primeiramente priorizem a prevenção, a correção imediata e o estabelecimento de padrões de qualidade contínua.

Palavras-chave: Contaminação de Alimentos. Segurança Alimentar. Controle e Fiscalização. Vigilância e Saúde Pública.

\begin{abstract}
Disease prevention and control must be part of the management system where improved net returns are a constant goal. Food-borne diseases are worldwide phenomena and microorganisms can adapt to new human food habits. Food handling must guarantee good food safety. Food can be contaminated from various environments and the emergency of pathogens is a result of the impact on food chains. Inadequate
\end{abstract}

Cristina Paiva de

S O US A

Universidade Federal de São Carlos. Centro de Ciências Biológicas e da Saúde, São Paulo, Brasil 
manipulation practices can explain how pathogens colonize and establishes in food and compromises food quality and safety. This review aimed to verify the factors related to pathogen dissemination and the impact in food technology, highlighting the good manipulation practices. It was emphasized the most prevalent pathogens such as Escherichia coli, Salmonella spp. and Staphylococcus aureus. Training food handlers and monitoring the food process unit can avoid food-borne diseases. Emphasis is need on prevention, correct manipulation practices and continuous quality control.

Keywords: Food Contamination. Food Safety. Control and Supervision. Public Health Attention.

\section{INTRODUÇÃO}

Com o crescimento e ampliação do processo de urbanização, torna-se emergente para o homem promover momentos de alimentação rápida. Apesar do crescimento deste setor, há poucos treinamentos direcionados aos manipuladores de alimentos, colaborando para que esta prática possa contribuir para se evitar que doenças veiculadas por alimentos atinjam a coletividade .

A qualidade e segurança de um alimento podem ser avaliadas por meio do controle de qualidade analítico. Esta técnica enfatiza a abordagem na inspeção durante a produção do alimento até a execução de testes físico-químicos, químicos e microbiológicos do produto final. Este critério pode ser realizado por órgãos governamentais e por técnicos da indústria e laboratórios de pesquisa, com o objetivo de verificar se o produto está de acordo com as leis e regulamentos do país e com as necessidades comerciais da indústria. $\mathrm{O}$ controle de qualidade do produto final nem sempre oferece a garantia de qualidade requerida. Isto pode ocorrer, entre outras razões, devido à dificuldade de se analisar as amostras em quantidade suficiente para obtenção de informes válidos, além do prolongado período para obtenção destas informações, uma vez que incluem exames microbiológicos, pessoal qualificado e custo elevado.

Ações direcionadas para a educação na manipulação adequada de alimentos podem contribuir para maximizar a segurança do manipulador no manuseio de alimentos, ampliar as perspectivas educacionais deste e fornecer à população um alimento seguro do ponto de vista microbiológico [16]. Do ponto de vista do consumidor, alguns fatores podem contribuir para a sua preferência pelo consumo de alimentos na rua, como: i) menor custo; ii) facilidade e rapidez no consumo e iii) praticidade [32].

Vários perigos podem ser veiculados por alimentos, como os de natureza física, química e microbiológica, sendo os biológicos os que mais causam doenças por este meio de transmissão [28, 29], uma vez que microrganismos são facilmente dispersos, têm ampla diversidade fisiológica, toleram condições extremas, são ubiquitários e podem contaminar e se multiplicar em vários produtos alimentícios, desde a matéria prima até o produto final. As doenças são causadas após o consumo de alimentos ou bebidas contaminadas com microrganismos e/ou seus metabólitos. Vários patógenos podem contaminar alimentos ou bebidas $[28,29,30]$.

Propõe-se verificar as condições de segurança microbiológica desde a produção 
até o consumo de alimentos, enfatizando as principais fontes de contaminação microbianas e a importância das boas práticas de manipulação para se obter uma qualidade higiênico-sanitária adequada, dando ênfase na vigilância à saúde para o consumo alimentar. Esta abordagem visa minimizar rotas e prevenir a transmissão de patógenos.

\section{MATERIAIS E MÉTODOS}

Esta revisão foi realizada a partir de uma verificação in situ de questões relacionadas à vigilância à saúde, e na coordenação/participação em projetos de extensão sobre o tema. Pretendeu-se verificar rotas de disseminação na transmissão de patógenos. Esta constatação foi observada por meio de trabalhos desenvolvidos por nosso grupo de pesquisa, tornando possível a elaboração desta visão reflexiva, pautada na viabilidade da educação continuada para o consumo de alimentos seguros do ponto de vista microbiológico e da saúde pública.

$\mathrm{Na}$ fundamentação desta revisão, utilizou-se como perfil analítico artigos envolvendo a vigilância à saúde no consumo alimentar. Foram consultadas bases de dados digitais como o MEDLINE (National Library of Medicine, Estados Unidos), LILACS (Literatura Latino-americana e do Caribe em Ciências da Saúde), SciELO (Scientific Electronic Library Online), a biblioteca comunitária da Universidade Federal de São Carlos (UFSCar) e a biblioteca setorial da Universidade de São Paulo (USP). Foram pesquisados e selecionados 34 artigos datados desde 1995 até 2013; a maioria das referências utilizadas variou entre 2003 e 2009. As palavras-chave consultadas foram "contaminação de alimentos"; "segurança alimentar"; "controle e fiscalização de bebidas e alimentos"; "vigilância sanitária”; "vigilância e saúde coletiva”. Os critérios utilizados para a seleção e análise de fontes foram a busca de artigos relacionados ao objeto de estudo e aqueles particularmente vinculados às palavras-chave, considerando-se como prioridades a relevância e fator de impacto das revistas, bem como a pertinência dos artigos com o assunto abordado.

Os estudos preliminares foram realizados por meio de experiências na docência $\mathrm{e}$ capacitação com turmas de merendeiras, auxiliares de merendeiras e manipuladores de alimentos em lanchonetes. Alguns cursos foram ministrados e outro foi desenvolvido com a colaboração da prefeitura do município de São Carlos-SP. Seis turmas foram submetidas a treinamento e verificou-se uma melhora (por meio de estudos de caso e avaliações práticas e teóricas) na compreensão dos fatores que envolvem a segurança de alimentos do ponto de vista higiênico-sanitário e de saúde pública.

Projetos de extensão também foram e continuam sendo realizados, fornecendo subsídios para prevenir, educar, corrigir, melhorar e ampliar a visão do manipulador de alimentos e de sua importância no processo de qualidade alimentar.

A elaboração de indicadores e medidas foi idealizada preparando-se e distribuindo-se livros e folhetos, para que o processo de educação e capacitação do manipulador seja continuado, contribuindo para a efetivação dos procedimentos transmitidos, compreendidos e aplicados. 


\section{RESULTADOS E DISCUSSÃO}

\section{Organismos Bacterianos em Alimentos}

Vários alimentos e bebidas podem veicular organismos bacterianos e/ou suas toxinas que, uma vez ingeridos, podem conduzir a uma infecção ou intoxicação alimen$\operatorname{tar}$ (Tabela 1).

Tabela 1 - Principais agentes etiológicos ocasionadores de doenças veiculadas por alimentos, sintomas, reservatório e referências

\begin{tabular}{|c|c|c|c|c|c|}
\hline AGENTE & DOENÇA & ALIMENTO & SINTOMAS & RESERVATÓRIO & REFERÊNCIAS \\
\hline E. Coli & $\begin{array}{l}\text { Infecção } \\
\text { alimentar, colite } \\
\text { (alguns patótipos) }\end{array}$ & $\begin{array}{l}\text { Vários, de } \\
\text { origem animal } \\
\text { e vegetal }\end{array}$ & $\begin{array}{l}\text { Dor abdominal, } \\
\text { diarreia com } \\
\text { sangue }\end{array}$ & $\begin{array}{l}\text { Homem e animais, } \\
\text { indicador fecal }\end{array}$ & {$[5,28,29,30]$} \\
\hline $\begin{array}{l}\text { Staphylococcus } \\
\text { spp. }\end{array}$ & $\begin{array}{l}\text { Intoxicação } \\
\text { alimentar }\end{array}$ & $\begin{array}{l}\text { Alimentos } \\
\text { animais crus, } \\
\text { leite, bolos }\end{array}$ & $\begin{array}{l}\text { Vômito, diarreia, } \\
\text { dor abdominal }\end{array}$ & Homem e animais & {$[3,9,25]$} \\
\hline Salmonella spp. & $\begin{array}{l}\text { Infecção } \\
\text { alimentar }\end{array}$ & $\begin{array}{l}\text { Aves, ovos, } \\
\text { maionese } \\
\text { caseira }\end{array}$ & $\begin{array}{l}\text { Febre, diarreia, } \\
\text { dor abdominal }\end{array}$ & Homem e animais & {$[2,15,24,27]$} \\
\hline
\end{tabular}

Mundialmente, surtos envolvendo diferentes patógenos em alimentos [32] são frequentes. No Brasil, os relatos se referem principalmente à Salmonella spp., Escherichia coli e Staphylococcus aureus. Esta incidência pode ser fundamentada levando-se em conta o perfil do manipulador de alimentos, a transmissibilidade dos patógenos e a falta de conhecimento sobre práticas seguras de manipulação [28, 30].

Coliformes fecais são bactérias utilizadas como indicadoras de condições higiênico-sanitárias de água e alimentos. A presença de indicadores como Escherichia coli em produtos sugere, provavelmente, uma contaminação posterior ao processamento [5] e supõe práticas inadequadas de manipulação e higiene [30].

Em trabalho de nosso grupo [23], conduzido com manipuladores de caldo de cana, detectou-se a presença de coliformes termo-tolerantes em sete amostras das mãos destes, e em uma amostra observou-se a presença de E. coli. Estes dados poderiam ser explicados por práticas inadequadas ou ausência de lavagem de mãos por manipuladores de alimentos, além da ausência de boas práticas de manipulação [23]. Allwood et al. [1], estudando manipuladores em estabelecimentos alimentícios, obtiveram 
resultados semelhantes, onde apenas $52 \%$ dos manipuladores de alimentos tinham conhecimento da importância da lavagem das mãos adequada.

Nos Estados Unidos, Musgrove et al. [20], analisando amostras de ovos, verificaram que Salmolnella spp. foi um dos gêneros identificados com maior freqüência. No Brasil, Santos e Kupek [26] descreveram o perfil epidêmico de surtos ocasionados pela bactéria e o principal alimento veiculador do microrganismo foi a maionese preparada artesanalmente. Barbosa Filho et al. [2], analisando a qualidade microbiológica de ovos em uma granja de aves confinadas, verificaram que, em ambientes fechados, o problema foi maximizado e as aves podem ser contaminadas por Salmonella imediatamente. Levantamentos realizados a partir de 2001 [27] mostram que Salmonella Enteritidis em materiais avícolas é o principal sorovar responsável por infecções humanas. Embora as carcaças de frango apresentem altas taxas de contaminação por Salmonella Enteritidis, são os ovos e seus derivados, principalmente a maionese caseira [27], os principais responsáveis pelos surtos humanos. Um trabalho realizado em São Paulo também detectou o consumo de ovos, cozidos de forma inadequada e contaminados com Salmonella Enteritidis, como responsável por um surto envolvendo 905 pessoas $[24]$.

Staphylococcus aureus é um patógeno humano capaz de causar várias doenças [25]. O consumo de alimentos onde há a produção da enterotoxina pela bactéria é um dos patógenos que mais acomete pessoas no mundo [3]. Um surto ocasionado por S. aureus ocorreu poucas horas após o consumo de alimentos, onde 4000 pessoas desenvolveram sintomas de intoxicação por este microrganismo [9]. A investigação epidemiológica revelou que os manipuladores de alimentos eram portadores de $S$. aureus enterotoxigênico [9], sendo eles a fonte de contaminação direta do alimento.

\section{Produção de Alimentos Seguros e Saúde}

Na indústria alimentar, os produtos devem possuir características de preferência do ponto de vista dos consumidores, das empresas e dos órgãos públicos, visando a promoção da saúde individual, familiar e coletiva, respectivamente. A preferência é um conjunto de características que o consumidor aprecia e valoriza, enquanto a segurança de um produto alimentício é o resultado da idoneidade (ausência de perigos para a saúde), integridade (ausência de fraude ou falsificação) e legalidade (ausência de defeitos ou adulterações) do alimento [30], atributos diretamente relacionados à segurança alimentar.

Um alimento é considerado seguro [30] quando contaminantes estão ausentes ou presentes em concentrações abaixo do limite de risco definido por legislação. Um alimento pode tornar-se de risco por: i) manipulação inadequada; ii) uso de matérias primas contaminadas; iii) contaminação e/ou crescimento microbiano elevado; iv) adição ou uso inadequado de aditivos químicos; v) poluição ambiental e degradação de nutrientes; vi) adição acidental de elementos físicos e vii) produção de toxinas no alimento.

Ações podem ser utilizadas para se obter um alimento seguro microbiologicamente. Dentre estas, é conveniente levar-se em conta a procedência ou fonte de 
contaminação dos alimentos [20,30]. Os microrganismos podem estar presentes no ambiente natural do homem (água, solo, ar), no próprio homem e nos seres vivos. Assim, em teoria, qualquer alimento que o homem consome pode estar contaminado por microrganismos.

\section{Fontes de Contaminação de Alimentos}

\section{1 - Contaminação a partir de vegetais, animais e solo}

As superfícies dos vegetais podem ser contaminadas a partir do solo, água, material fecal, ar e animais. Em experimentos com E. coli, marcada com moléculas bioluminescentes, observou-se que a bactéria pode ser internalizada por raízes de espinafre e que fatores como competitividade entre microrganismos do solo representam diferenças nos níveis de contaminação [34].

Produtos de origem animal podem ser contaminados a partir da microbiota endógena do animal, das mãos do manipulador, do ambiente, dos procedimentos de higiene da ordenha, do acondicionamento do leite e transporte. Vetores também têm um papel importante. Jesus et al. [14], verificaram que insetos são veiculadores de patógenos, podendo atuar como agentes de contaminação cruzada.

Os solos contêm maior variedade e quantidade de microrganismos, e estes podem chegar até a água através do ar, da superfície das plantas e dos animais.

\section{2 - Contaminação a partir da água, material fecal e do ar}

Vários microrganismos podem ser incorporados aos alimentos no processo de lavagem dos mesmos se for utilizada água de qualidade microbiológica inadequada [31]. Dentre estes, os coliformes são um dos grupos mais representativos. Assim, o risco de transmissão de patógenos pode ser influenciado por i) nível de contaminação; ii) persistência do patógeno na água, solo e corpos d'água e iii) rota de exposição.

A contaminação aérea é importante do ponto de vista sanitário e econômico [16, 33]. Os microrganismos podem estar presentes no ar, suspensos em partículas sólidas ou pequenas gotas de água. Microrganismos que permanecem no ar são mais resistentes ao dessecamento, dependendo também do movimento do ar, luz (solar e artificial) e umidade.

Em trabalho conduzido para verificação da incidência de contaminação a partir do ar em uma indústria beneficiadora de aves, observou-se que os animais vivos eram a maior fonte de bioaerossóis, sendo pertinente a ênfase nas medidas que evitassem este problema [33].

Uma das formas de se evitar a contaminação aérea seria a utilização de um sistema com controle de clima (temperatura e umidade relativa), para diminuir a propagação de aerossóis [33]. Um sistema tecnológico não muito sofisticado poderia ser usado. Em trabalho realizado por Lues et al. [18] é mostrado que, para evitar a propagação de bioaerossóis, uma atenção especial deve ser dada em áreas de recebimento e processamento de animais. Essas práticas podem levar à obtenção de um produto final 
com menor número de contaminantes.

\section{3 - Contaminação durante a industrialização}

A contaminação pode ocorrer antes do processamento ou durante a manipulação e tratamento, a partir de equipamentos, utensílios, matérias primas e manipulador [23].

\section{a) Manipuladores de alimentos}

Os microrganismos presentes em manipuladores podem ser provenientes do ambiente ou endógenos $[23,30]$. Em um trabalho conduzido na Nigéria, observou-se que um percentual expressivo de manipuladores não conhecia ou adotava práticas inadequadas à manipulação higiênica de alimentos [21]. Estabelecendo-se um paralelo entre as formas de manipulação e os manipuladores de alimentos na Nigéria e no Brasil, é possível visualizar resultados similares. Os índices de microrganismos presentes nestes casos supõem origem tanto endógena como ambiental. Estas constatações poderiam explicar os resultados similares.

\section{b) Utensílios, equipamentos e superfícies}

Vários recipientes, equipamentos e superfícies têm um papel importante como fontes de contaminação de alimentos $[23,30]$.

A implantação e o uso de um sistema de análises de perigos e pontos críticos de controle (APPCC) visam garantir a segurança de produtos alimentícios. O APPCC é baseado nos seguintes princípios: i) realização de análise de perigos, da matéria prima até o produto final; ii) identificação de pontos críticos de controle; iii) estabelecimento de limites para medidas preventivas; iv) estabelecimento de critérios para monitorar pontos críticos; v) implantação de ações corretivas; vi) uso de sistemas de registro de dados e vii) implantação de sistema para auto-correção. A APPCC pode ser utilizada na prevenção e detecção dos perigos, contribuindo para a segurança de consumo alimentar.

\section{Saúde e Consumo de Alimentos Seguros}

A segurança de alimentos está diretamente relacionada a práticas que envolvem desde a obtenção da matéria prima alimentar, até o produto final. Trabalho realizado no Brasil por Cardoso et al. [8] relata que o comércio de alimentos de rua é crescente e o risco sanitário para seu consumo é elevado, dados similares aos detectados por outros autores [11, 23]. Devido à urbanização, a utilização de alimentação fora de casa é crescente [11] e uma opção viável para grande parte da população [8]. No Brasil, a prática de alimentação fora de casa está relacionada a hábitos urbanos e ao fenômeno da globalização, podendo ser comprovada pelos padrões alimentares semelhantes de culturas de outros continentes [11].

O Conselho Nacional de Segurança Alimentar e Nutricional (CONSEA) [10] 
interpreta a segurança, na obtenção e consumo de alimentos, como um direito de todos ao acesso regular e permanente aos alimentos de qualidade em quantidade suficiente, sem comprometer o acesso a outras necessidades essenciais, tendo como princípios a promoção da saúde, respeito da diversidade cultural, social, econômica e ambiental sustentável. Nesta contextualização, a saúde coletiva está permeada de conceitos salutares que devem ser aliados à prática, enfatizando-se a importância da incorporação da qualidade higiênico-sanitária aplicada à qualidade de consumo de alimentos, desde o indivíduo até a população. A Legislação de San-Losan [17] propõe diretrizes e prioridades da política do plano nacional de segurança alimentar e nutricional, considerando deliberações de SAN. Os órgãos de saúde devem monitorar e acompanhar as ações relativas à política e ao plano de SAN, além de apoiar entidades da sociedade civil na discussão e implementação de ações públicas de segurança alimentar e nutricional.

Devido ao elevado consumo de alimentos fora de casa $[8,23]$ nas cidades brasileiras, verifica-se a necessidade de abrangência de informações aos consumidores finais. Bezerra et al., [4] reportaram que a maior frequência de alimentação fora do domicílio é representada pelo consumo de alimentos com alto aporte energético. Esses autores observaram que $40 \%$ dos entrevistados alimentavam-se fora de casa, com variação de $13 \%$ entre a população idosa no Sul do Brasil a 51\% entre os adolescentes no Sudeste. Verificou-se a diminuição desta prática com o aumento da idade e da renda em todo o Brasil, sendo maior a frequência entre os homens na área urbana. Estes dados são interessantes, pois se verifica a necessidade de realizar ações que melhorem as práticas de consumo de alimentos. Dados produzidos pelo IBGE [13] obtidos por meio da Pesquisa de Orçamentos Familiares (POF 2008-2009) mostram resultados similares, onde há uma tendência ao crescimento da alimentação fora do lar relativa à idade e regiões do país. Também utilizando os dados da POF 2008-2009, Hoffman [12] comparou o perfil de comensais dentro e fora do domicílio. Esse autor verificou que o consumo de vitamina $\mathrm{C}$ e de carboidratos foi superior em relação aos outros nutrientes, mas o teor de lipídios foi menor. Esses resultados sugeriram uma possibilidade de uso racional de alimentação fora de casa.

Muitos alimentos são perecíveis e facilmente deteriorados, principalmente devido a fatores humanos e ambientais como o clima tropical [23]. Desta forma, é importante a capacitação do manipulador, a veiculação da informação ao consumidor e a vigilância realizada pelos órgãos públicos competentes. Esta estratégia de ação tri-direcionada pode contribuir sobremaneira para a promoção da saúde, a prevenção de doenças veiculadas por alimentos e a proteção da saúde coletiva.

Trabalho realizado por Oliveira et al. [22] detectou que as cozinhas avaliadas de creches públicas e filantrópicas do município de São Paulo ofereciam riscos de contaminação de alimentos. Dentre os vários fatores de risco, os autores observaram que as ações inadequadas dos manipuladores eram os mais graves. Um estudo conduzido por Campos [7] identifica quatro formas para se produzir saúde: i) por meio de transformações econômicas, sociais e políticas, com aquisição de padrão saudável de vida; ii) realizando vigilância à saúde e enfatizando a prevenção de doenças; iii) aplicando práticas clínicas e de reabilitação e iv) enfocando no atendimento de urgências 
e emergências, com utilização de intervenção imediata, preservando a vida. Nesta visão ampliada, a vigilância no consumo alimentar, com estabelecimento de estratégias para minimização de transmissão de patógenos, está inserida nos quatro níveis apresentados. Nos Estados Unidos, Kassa et al [15] verificaram que a segurança de alimentos é uma prática importante na saúde coletiva, e o consumo de alimentos fora de casa está muitas vezes associada à surtos de Doenças Veiculadas pelos Alimentos (DVA’s). O treinamento para segurança e certificação são métodos utilizados para redução destes surtos.

Trabalho realizado por Moreira et al [19], estudando uma amostra entre 2000 e 2004 sobre contaminação em Juiz de Fora-MG, destaca a importância do conhecimento em intoxicações, incluindo as alimentares. Um dos grupos mais vulneráveis apresentados neste estudo foi o de crianças e idosos; demonstrou-se também que as intoxicações podem ser minimizadas pela ampliação do conhecimento de origens, evolução e prevenção [19]. A diversidade de vetores e reservatórios tem tendência a aumentar [6] e mudanças em condições climáticas podem contribuir para o estabelecimento de patógenos emergentes.

Com base nestas considerações, pode-se trabalhar conjuntamente com os vários setores envolvidos na segurança alimentar e desenvolver ações públicas, de saúde pública, para a melhoria da qualidade de alimentos destinados às diversas populações consumidoras. A implantação de programas e recomendações para uma adequada saúde alimentar de populações, aliada aos esforços políticos de práticas sanitárias públicas de preparo e consumo de alimentos seguros, visa, em última instância, assegurar melhores níveis da saúde comunitária.

\section{CONCLUSÕES}

A aplicação de critérios microbiológicos direcionados à análise de refeições realizadas fora de casa são utilizados para se fabricar, produzir e consumir produtos com qualidade. $\mathrm{O}$ treinamento de manipuladores, monitoramento de produtos e unidades de processamento oferecem formas de se evitar doenças veiculadas por alimentos. É importante estar ciente da importância da lavagem de mãos, do emprego correto de tempo e temperatura de cocção, de ser evitada a contaminação cruzada, de se armazenar adequadamente os alimentos e de ser incentivada a capacitação dos manipuladores de alimentos, enfatizando-se as boas práticas de manipulação. Programas educacionais envolvendo práticas para segurança alimentar devem ser direcionados aos manipuladores. O maior incentivo deve ser concentrado no desenvolvimento de políticas públicas de saúde, legislativas e priorização de práticas que, primeiramente, utilizem a prevenção através de capacitação, correção imediata e o estabelecimento de padrões de qualidade contínua. Uma das maneiras de se obter estes benefícios é o uso de programas de análise de perigos e pontos críticos de controle. 


\section{REFERÊNCIAS}

[1] ALLWOOD, P. B.; JENKINS, T.; PAULUS, C.; JOHNSON, L.; HEDBERG, C. W. Hand washing compliance among retail food establishment workers in Minnesota. Journal of Food Protection, v. 12, p. 2825-2828, 2004. Disponível em: <http://www.hi-tm.com/Documents2004/JFP-67\%2312-p2825-handwash-in-MN.pdf $>$. Acesso em 18 set. 2014.

[2] BARBOSA FILHO, J. A. D.; SILVA, M. A. N.; SILVA, I. J. O.; COELHO, A. A. D. Egg quality in layers housed in different production systems and submitted to two environmental conditions. Brazilian Journal of Poultry Science. Campinas, v. 8, p. 23-28, 2005. Disponível em: http://www.scielo.br/scielo. php?script $=$ sci_arttext\&pid $=S_{1516-635} \mathrm{X}_{2006000100003}>$. Acesso em 18 set. 2014. DOI: http://dx.doi.org/10.1590/S1516-635X2006000100003

[3] BERGDOLL, M. S. Staphylococcus até onde sua importância em alimentos? Higiene Alimentar, v. 14, p. 32-40, 2000.

[4] BEZERRA, I. N.; SOUZA, A. M.; PEREIRA, R. A.; SICHIERI, R. Consumo de alimentos fora do domicílio no Brasil. Revista de Saúde Pública, São Paulo, v. 47, p. 200s-211s, 2013. Disponível em: http://www.scielo.br/scielo. php?pid=So034-89102013000700006\&script=sci_arttext $>$. Acesso em 18 set. 2014. DOI: http://dx.doi.org/10.1590/ So034-89102013000700006

[5] BLOOD, R. M.; CURTIS, G. D. W. Media for total Enterobacteriaceae, coliforms and Escherichia coli. International Journal of Food Microbiology, v. 26, p. 93-115, 1995. Disponível em: http://www.sciencedirect.com/ science/article/pii/o16816059400040D >. Acesso em 18 set. 2014. DOI: 10.1016/o168-1605(94)00040-D

[6] BOXAL, L. A.; HARDY, A.; BEULKE, S.; BOUCARD, T.; BURGIN, L.; FALLON, P. et al. Impacts of climate change on indirect human exposure to pathogens and chemicals from agriculture. Ciência Saúde Coletiva, Rio de Janeiro, v. 15, n. 3, p. 743-756, 2010. Disponível em: http://www.scielo.br/scielo. php?script=sci_artext\&pid=S1413-81232010000300017>. Acesso em 18 set. 2014. DOI: http://dx.doi.org/10.1590/S1413-81232010000300017

[7] CAMPOS, G. W. S. Saúde pública e saúde coletiva: campo e núcleo de saberes e práticas. Ciência Saúde Coletiva, Rio de Janeiro, v. 5, n. 2, p. 219230, 2000. Disponível em: <http://www.scielo.br/scielo.php?pid=S1413$-81232000000200002 \& s c r i p t=s c i \_a r t t e x t>$.Acesso em 18 set. 2014.DOI: http:// dx.doi.org/10.1590/S1413-81232000000200002

[8] CARDOSO, R. C. V.; SANTOS, S. M. C.; SILVA, E. O. Comida de rua e intervenção: estratégias e propostas para o mundo em desenvolvimento. Ciência Saúde Coletiva, Rio de Janeiro, v. 14, n. 4, p. 1215-1220, 2009. Disponível em: <http://www.scielo.br/scielo.php?pid=S1413$-81232009000400027 \&$ script $=$ sci_arttext $>$. Acesso em 18 set. 2014. DOI: http://dx.doi.org/10.1590/ S1413-81232009000400027 
[9] CARMO, L. S.; CUMMINGS, C.; LINARDI, V. R.; DIAS, R. S.; SOUZA, J. M.; SENA, M. J.; et al. A case study of a massive staphylococcal food poisoning incident. Food Pathology Diseases, v. 1, p. 241-246, 2004. Disponível em: <http://online.liebertpub.com/doi/abs/10.1089/fpd.2004.1.241>. Acesso em 18 set. 2014. DOI: $10.1089 / \mathrm{fpd} .2004 \cdot 1.241$

[10] Conselho Nacional de Segurança Alimentar e Nutricional. Princípios e diretrizes de uma política de segurança alimentar e nutricional. 2004 [80 p.]. Disponível em: <http://www.fomezero.gov.br/documentos >. Acesso em: 20 jan. 2014.

[11] GARCIA, R. W. D. Reflexos da globalização na cultura alimentar: considerações sobre as mudanças na alimentação urbana. Revista Nutrição, v. 16, n. 4, p. 483-492, 2003. Disponível em: <http://<http://www.scielo.br/scielo. php?pid $=S_{1415}-52732003000400011 \&$ script $=$ sci_abstract\&tIng $=$ pt $>$. Acesso em 18 set. 2014. DOI: http://dx.doi.org/10.159o/ S1415-52732003000400011

[12] HOFFMANN, R. Comparando a alimentação dentro e fora do domicílio, no Brasil, em 2008-2009. Segurança Alimentar e Nutricional, v. 20(1), p. 1-12, 2013.

[13] Instituto Brasileiro de Geografia e Estatística (IBGE). Pesquisa de Orçamentos Familiares 2008-2009: análise do consumo alimentar pessoal no Brasil. Rio de Janeiro: IBGE; 201.

[14] JESUS, A. J.; OLSEN, A. R.; BRYCE, J. R.; WHITING, R. C. Quantitative contamination and transfer of Escherichia coli from foods by houseflies, Musca domestica L. (Diptera: Muscidae). International Journal Food Microbiology, v. 93, p. 259-162, 2004. Disponível em: <http://www.sciencedirect. com/science/article/pii/So1681605030060X>. Acesso em 18 set. 2014. DOI: 10.1016/j.ijfoodmicro.2003.12.003

[15] KASSA, H.; SILVERMAN, G. S.; BAROUDI, K. Effect of a manager training and certification program in food safety and hygiene in food service operations. Environmental Health Insights, v. 6, n. 4, p. 13-20, 2010. Disponível em: <http://www.ncbi.nlm.nih.gov/pmc/articles/PMC2879608/>. Acesso em 18 set. 2014. DOI: 10.4137/EHI.S4717

[16] LEVINGER, B. School feeding, school reform, and food security: connecting the dots. Food Nutrition Bulletin, v. 26, p. 170-178, 2005. Disponível em: $<$ http://nsinf.publisher.ingentaconnect.com/search/article?optionı=tka\&va lue1=school\&operator $9=$ AND\&option9=publication\&value $9=$ nsinf\&sortDe scending $=$ true $\&$ sortField $=$ default $\&$ pageSize $=10 \&$ index $=1>$. Acesso em 18 set. 2014.

[17] Legislação e Políticas públicas de SAN-LOSAN. Disponível em: <http:// plataforma.redesan.ufrgs.br/biblioteca/mostrar_bib.php?COD_ARQUI$\mathrm{VO}=17615>$ Acesso em 20 jan. 2014.

[18] LUES, J. F. R.; THERON, M. M.; VENTER, P.; RASEPHEI, M. H. R. Microbial composition in Bioaerosols of a high-throughput chicken-slaughtering facility. Poultry Science, v. 86, p. 142-149, 2007. Disponível em: <http:// ps.oxfordjournals.org/content/86/1/142.abstract> Acesso em 18 set. 2014. DOI: $10.1093 / \mathrm{ps} / 86.1 .142$ 
[19] MOREIRA, C. S.; BARBOSA, N. R.; VIEIRA, R. C. P. A.; CARVALHO, M. R.; MARANGON, P. B.; SANTOS, P. L. C. et al. Análise retrospectiva das intoxicações admitidas no hospital universitário da UFJF no período 20002004. Ciência Saúde Coletiva, Rio de Janeiro, v. 15, n. 3, p. 879-888, 2010. Disponível em: <http://www.scielo.br/scielo.php?script=sci_arttext\&pi $\mathrm{d}=\mathrm{S}_{1413}-81232010000300031>$ Acesso em 18 set. 2014. DOI: http://dx.doi. org/10.1590/S1413-81232010000300031

[20] MUSGROVE, M. T.; NORTHCUTT, J. K.; JONES, D. R.; COX, N. A.; HARRISON, M. A. Enterobacteriaceae and related organisms isolated from shell eggs collected during commercial processing. Poultry Science, v. 87, n. 6, p. 1211-1218, 2008. Disponível em: Disponível em: <http://ps.oxfordjournals.org/ content/87/6/1211.long > Acesso em 18 set. 2014. DOI: 10.3382/ps.2007-00496

[21] OKOJIE, O. H.; WAGBATSOMA, V. A.; IGHOROGE, A. D. An assessment of food hygiene among food handlers in a Nigerian university campus. Niger Postgraduate Medical Journal, v. 12, p. 93-96, 2005. Disponível em: <http://www.tjmrjournal.org/article.asp?issn=1119-0388; year=2014; volume=1 7 ; issue $=1$; spage $=10$; epage $=15$; aulast $=$ IfeadLike $>$. Acesso em 18 set. 2014. DOI: 10.4103/1119-0388.130175

[22] OliveIRA, M. N.; BRASIL, A. L. D.; TADDEI, J. A. A. C. Avaliação das condições higiênico-sanitárias das cozinhas de creches públicas e filantrópicas. Ciência Saúde Coletiva, Rio de Janeiro, v. 13, n. 3, p. 1051-1060, 2008. Disponível em: <http://www.scielo.br/scielo.php?script=sci_arttext\&pid $=\mathrm{S}_{1413}-81232008000300028>$. Acesso em 18 set. 2014. DOI: http://dx.doi. org/10.1590/S1413-81232008000300028

[23] OLIVEIRA, A. C. G.; SEIXAS, A. S. S.; SOUSA, C. P.; SOUZA, C. W. O. Microbiological evaluation of sugarcane juice sold on streets and vendors handling conditions in São Carlos, SP. Cadernos Saúde Pública, Rio de Janeiro, v. 22, n. 5, p. 1111-1114, 2006. Disponível em: <http://www.scielo.br/scielo.php?script=sci arttext\&pid=So102-311X2006000500024>. Acesso em 18 set. 2014. DOI: http:// dx.doi.org/10.1590/So102-311X2006000500024

[24] PERESI, J. T.; ALMEIDA, I. A.; LIMA, S. I.; MARQUES, D. F.; RODRIGUES, E. C.; FERNANDES, A. S., et al. Food borne disease outbreaks caused by Salmonella enteritidis. Revista Saúde Pública, São Paulo, v. 32, p. 477-483, 1998. Disponível em: <http://www.scielo.br/scielo.php?script=sci_arttext\& pid=So034-89101998000500011 >. Acesso em 18 set. 2014. DOI: http://dx.doi. org/10.1590/So034-89101998000500011

[25] RATTI, R. P.; SOUSA, C. P. Meticillin resistant Staphylococcus aureus (MRSA) and nosocomial infections. Revista Ciência Farmacêutica Básica Aplicada, São Carlos, v. 30, p. 9-15, 2009.

[26] SANTOS, S. M.; KUPEK, E. Serial outbreaks of food-borne disease in Blumenau, Brazil, caused by Salmonella enteritidis. Brazilian Journal of Infectious Diseases, v. 4, p. 275-278, 2000. Disponível em: http://serv-bib.fcfar.unesp.br/seer/ index.php/Cien_Farm/article/viewFile/550/799>. Acesso em 18 set. 2014. 
[27] SILVA, E. M.; DUARTE, A. Salmonella Enteritidis em Aves: Retrospectiva no Brasil. Revista Brasileira Ciência Avícola, Campinas, v. 4, n. 2, p. 85100, 2002. Disponível em: <http://www.scielo.br/scielo.php?pid=S1516$-635 \mathrm{X} 2002000200001 \&$ script $=$ sci_arttext $>$. Acesso em 18 set. 2014. DOI: http://dx.doi.org/10.1590/S1516-635X2002000200001

[28] SOUSA, C. P. The strategies of Escherichia coli pathotypes and health surveillance. Revista Brasileira de Vigilância Sanitária, São Paulo, v. 1, p. 65-70, 2005.

[29] SOUSA, C. P. The impact of food manufacturing practices on food borne diseases. Brazilian Archives Biology Technology, Curitiba, v. 51, n. 4, p. 615-623, 2008. <http://www.scielo.br/scielo.php?script=sci_arttext\&pid $=$ S1516-89132008000400020 $>$ Acesso em 18 set. 2014. DOI: http://dx.doi. org/10.1590/S1516-89132008000400020

[30] SOUZA, E. L.; SILVA, B. H. C.; SOUSA, C. P. Manipuladores como causas potenciais de contaminação de alimento enteral. Infarma, João Pessoa, v. 15, p. 71-73, 2003. Disponível em: <http://www.cff.org.br/sistemas/geral/revista/ pdf/84/io5-microbiana.pdf $>$. Acesso em 18 set. 2014.

[31] STEELE, M.; ODUMERU, J. Irrigation water as source of foodborne pathogens on fruit and vegetables. Journal Food Protection, v. 67, p. 2839-2849, 2004.

[32] TAYLOR, J. P.; EVERS, S.; MCKENNA, M. Determinants of healthy eating in children and youth. Canadian Journal of Public Health, v. 3, p. 2026, 2005. Disponível em: <http://journal.cpha.ca/index.php/cjph/article/ view/1501/1690>. Acesso em 18 set. 2014.

[33] VENTER, P.; LUES, J. F.; THERON, H. Quantification of bioaerosols in automated chicken egg production plants. Poultry Science, v. 83, p. 1226-1231, 2004. Disponível em: <http://ps.oxfordjournals.org/content/83/7/1266.abstract>. Acesso em 18 set. 2014. DOI: 10.1093/ps/83.7.1226

[34] WARRINER, K., IBRAHIM, F.; DICKINSON, M.; WRIGHT, C.; WAITER, W. M. Interaction of Escherichia coli with growing salad spinach plants. Journal of Food Protection, v. 66, p. 1790-1797, 2003.

CRISTINA PAIVA DE souSA professora doutora associada do Departamento de Morfologia e Patologia da Universidade Federal de São Carlos (DMP-UFSCar) - e-mail: prokarya@ufscar.br 